\title{
Analysis of Successful Initiations of Three Children With Hearing Loss Mainstreamed in Kindergarten Classrooms
}

\author{
Melissa Murphy Hulsing \\ Barbara Luetke-StahIman \\ Diane Frome Loeb \\ Peggy Nelson \\ Jane Wegner
}

The University of Kansas, KS

ABSTRACT: The communicative interactions of three mainstreamed children who are deaf or hard of hearing (deaf $/ \mathrm{HOH}$ ) were investigated. These children were matched with a classmate who had normal hearing $(\mathrm{NH})$ according to chronological age, sex, race, and socioeconomic status (SES). All subjects were white females approximately 5 years of age. The subjects were videotaped while involved in normal classroom activities. The videotaped interactions were coded for: (a) activity, (b) play level, (c) partner, (d) interactive status, and (e) mode of communication.

Dyad interactions were analyzed for average length, frequency, and total number of interactions. The children's interactions varied by child and classroom setting. Results regarding the success of initiations were that one subject who is deaf initiated less often and was more successful than her peer with $\mathrm{NH}$; the other subject who is deaf initiated less often and was less successful than her peer with $\mathrm{NH}$; and the subject who is $\mathrm{HOH}$ initiated more often and was less successful than her peer with NH. Factors found to affect the success of initiations were the number of children involved and the accompaniment of actions and/or gestures with spoken or signed communication. These results suggest that children who are deaf/ $\mathrm{HOH}$ often are less successful at initiations than children with $\mathrm{NH}$, but the success of the initiations by children who are deaf/HOH may depend on more variables than past research has led us to believe (Arnold \& Tremblay, 1979; Lederberg, Ryan, \& Robbins, 1986; Levy Shiff \& Hoffman, 1985; Vandell \& George, 1981). Possible factors that contribute to interactions and successful initiations by children who are deaf/HOH are discussed.

KEY WORDS: hearing loss and deafness, language development, assessment, mainstream, kindergarten

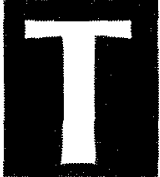

he least restrictive environment provision of Public Law 94-142 has resulted in increased efforts to mainstream children with handicaps into typical classrooms. According to Schildroth (1988), the enrollment pattern of children and youths who are deaf or hard of hearing (deaf/HOH) has changed greatly over the last decade. Specifically, there has been an overall decrease in the number of students who are deaf/HOH who receive special educational services in nonintegrated schools, while at the same time, the number of students being educated in their local schools has increased. These children are able to function in regular classroom settings (Northcott, 1978) where they are presumably able to benefit from interactions with models who have normal hearing $(\mathrm{NH})$, to experience more realistic social consequences, and to observe other children's appropriate communicative interactions

(Guralnick, 1980).

According to Coie and Kupersmidt (1983), a key characteristic of social acceptance for children with $\mathrm{NH}$ is the ability to engage in social conversations. However, studies have found that interactions between children with NH and children who are deaf/HOH often are unsuccessful.

\section{SOCIAL CONVERSATIONS OF CHILDREN WITH NORMAL HEARING}

Although children are fairly adept at social interchanges at an early age, there are several factors that may lead to breakdowns in communication. These breakdowns can occur at any point during the interaction. One vulnerable point is at the beginning of the interaction, when the speaker is initiating the conversation with a given partner. For 
example, Ervin-Tripp and Gordon (1986) reported that children between 2-4 years of age have a difficult time gaining the addressee's attention and their attention-getting devices are less specific than those of older children (e.g., "Look" instead of "Look Sally").

Ervin-Tripp (1979) reported that children between 4-8 years of age experience a greater range of social communication. During this time, children become more aware of the need to gain the attention of their addressee and they begin to use more effective attention-getting devices. At this time, gaze and proximity begin to play a role between two- and three-person interactions (Craig \& Gallagher, 1983). Children also increase the likelihood of noticing when a peer is preoccupied and are less likely to try to gain that peer's attention.

The two most powerful predictors of initiation failure in children are unclear utterances (i.e., all or some of the words are unclear) and fragmentary or grammatically unclear utterances (Mueller, 1972). The probability of failure also is high when the speaker does not look at the listener, uses no attentional techniques, and speaks about his or her own activity. Because younger children are not adept at situations in which they must compete for attention or are interrupted, they have fewer difficulties with turn-taking when the conversation is between two instead of three or more children (Ervin-Tripp, 1979).

\section{SOCIAL INTERACTIONS OF CHILDREN WITH SPECIAL NEEDS}

Children with disabilities tend to interact differently than their peers who are developing normally. Some of the past research involved children with mental retardation. Cunningham, Reuler, Blackwell, and Deck (1981) found that children with mild-to-moderate mental retardation were less interactive, less responsive, and spent more time in solitary play when playing with their mothers than when playing with their peers who were developing normally.

Other research has focused on children with limited communication skills. These children also tended to exhibit different communicative behaviors from their peers who develop normally. In general, children with limited communication skills participated less often in peer interactions (Hadley \& Rice, 1991; Rice, Sell, \& Hadley, 1991). These children who initiated interactions less often than their peers who were developing normally (Conti-Ramsden \& Friel-Patti, 1983) were more likely to initiate to adults and to shorten their responses or use nonverbal responses (Rice et al., 1991), and were less likely to respond to the initiation attempts of their peers (Hadley \& Rice, 1991).

According to Hadley and Rice (1991), children with limited communication skills were less likely to receive responses to their initiations than were children with normal development. These researchers suggest that peers with normal development may have been less likely to respond to the initiations partially because of the limited intelligibility of some of the children who are speech delayed or the limited attention-getting abilities of these children.

\section{SOCIAL INTERACTIONS OF CHILDREN WHO ARE DEAF/HOH}

There is little research concerning the social interactions of children who are deaf/HOH. One particularly noteworthy study was conducted by Vandell and George (1981). They concluded that children with $\mathrm{NH}$ preferred to interact with peers who also have $\mathrm{NH}$ and that children who are deaf/ $\mathrm{HOH}$ preferred to interact with peers who also are deaf/ $\mathrm{HOH}$. The researchers also concluded that although there were no significant differences between the number of interactions of children with $\mathrm{NH}$ and the number of interactions of children who are deaf/ $\mathrm{HOH}$, there was a significant difference between the amount of time spent in the interactions.

The researchers also found that preschoolers who are deaf/HOH attempted to initiate significantly more often than their peers with $\mathrm{NH}$; however, these initiations were more likely to be ignored or rejected by their peers. Although vocalizations, smiles, and other combined modality acts were used commonly by the children who are deaf/HOH to initiate an interaction with another child, children with NH rarely used combined modalities to initiate to their peers who are deaf/HOH. Moreover, the researchers concluded that the initiations of children who are deaf/HOH were more likely to fail simply because their peers with NH did not respond, whereas failure at initiations by children with $\mathrm{NH}$ often was the result of the use of inappropriate signals that were impossible for the children who are deaf/HOH to receive.

In a study conducted in 1982, Vandell, Anderson, Ehrhardt, and Wilson attempted to modify the behaviors of preschoolers with $\mathrm{NH}$ who refused to interact with peers who are profoundly deaf by making children with $\mathrm{NH}$ more aware of the abilities of children who are deaf/HOH. Although the children with $\mathrm{NH}$ were exposed to many activities related to deafness, children who are deaf/HOH continued to produce unsuccessful initiations when paired with children with $\mathrm{NH}$. The preference of children with $\mathrm{NH}$ to communicate with peers with $\mathrm{NH}$ and children who are deaf/HOH to communicate with peers who are deaf/HOH was not judged to be a result of social ineptness, but was attributed to the fact that the children who are deaf/HOH communicated in a different modality than the children with NH (Levy Shiff \& Hoffman, 1985).

Lederberg, Ryan, and Robbins (1986) concluded that children who are deaf used vocalizations frequently, but these vocalizations rarely were spoken words that led to interactions with peers with $\mathrm{NH}$. The researchers also concluded that children who are deaf only used formal language a small percentage of the time; instead, they used a large percentage of other visual communicative modes, which served to sustain social interactions with children with NH. Children with NH learned to use gestures and head nods equal to that of children who are deaf when paired with a familiar child who is deaf; however, peers with NH did not modify their communication appropriately to an unfamiliar child who is deaf. Children with NH modified their communication because of their familiarity 
with the specific child who is deaf, not because of an improved understanding of the deaf population as a whole. These findings were similar to those of Vandell et al. (1982) in that children with NH did not modify their communication solely because of a child's hearing status.

Children who are deaf/HOH are typically unsuccessful at initiating communication and spend less time in communication activities than their peers with NH. More specifically, the initiations of interactions between children with $\mathrm{NH}$ and children who are deaf/HOH often are a point of breakdown. Children who are deaf/HOH attempt to initiate more often than children with $\mathrm{NH}$ (Vandell \& George, 1981). However, once either group attempts an initiation, neither group is more likely to respond, therefore making the initiation successful (Arnold \& Tremblay, 1979). This finding has been attributed to the fact that often times, children with NH simply do not respond (Vandell \& George, 1981). On the other hand, the children who are deaf/HOH failed to respond to the initiations of children with $\mathrm{NH}$ because the children with $\mathrm{NH}$ used spoken words that the children who are deaf/HOH were unable to understand (Arnold \& Tremblay, 1979; Levy Shiff \& Hoffman, 1985; Vandell \& George, 1981). Children who are deaf/HOH were more likely to use combined modalities to initiate interactions, which led to more successful initiations. Thus, even though the child who is deaf/HOH is mainstreamed into a classroom with peers with $\mathrm{NH}$, the children do not necessarily communicate competently with each other.

There is a need to further investigate the communicative interactions of young children who are deaf $/ \mathrm{HOH}$ and children with NH. An interaction is the reciprocal action of an initiation and the responses that follow. An initiation is the beginning of discourse that is clearly not a part of an existing interaction. This study was designed to obtain a greater understanding of what might cause the initiations of communication by children who are deaf/HOH to be less successful than those of peers with $\mathrm{NH}$ when in mainstreamed classrooms. By looking at different aspects of communication (i.e., play level, mode of communication, and success of initiation), it was hypothesized that factors contributing to the less successful communication of children who are deaf/HOH could be identified. The specific purpose of the study was to examine the number of interactions, the average length of the interactions, and the frequency of interactions by the subjects with NH as compared to the subjects who are deaf/HOH. The study also investigated the total number of initiations and the number of successful initiations by subjects with $\mathrm{NH}$ as compared to subjects who are deaf/HOH. In addition, the study investigated with whom the child intended to initiate interactions.

\section{SUBJECTS}

Six female children ( 3 deaf/HOH, 3 with $\mathrm{NH}$ ) served as subjects. The subjects with $\mathrm{NH}$ were matched with a subject who was deaf/HOH with regard to sex, race, and chronological age (+/- 6 months) (see Table 1 ).

Subjects' socioeconomic status (SES) ranged from Level I to Level II (Hollingshead \& Redlich, 1958). A Level I rating on the instrument represents the highest level of social position based on occupation and education.

The language ability of all subjects was tested before data collection. Results of this testing appear in Table 2. Norms used were based on children with $\mathrm{NH}$ with the exception of the Grammatical Analysis of Elicited Language-Pre Sentence Level (Moog, Kozak, \& Geers, 1983). There was some variability in percentile scores as a result of the different areas of language tested and the variety of tests. All test scores were within or above normal limits.

Subjects with NH passed a hearing screening conducted at the time they entered kindergarten. The unaided hearing loss of the children who are deaf/HOH ranged from severe to profound across the frequencies of 500, 1000, and 2000 $\mathrm{Hz}$. Aided hearing acuity ranged from $30 \mathrm{~dB}$ to $50 \mathrm{~dB}$ across these same frequencies. One subject (B-D) evidenced aided hearing acuity of $47 \mathrm{~dB}$ as a result of cochlear implant surgery 6 months before this study and was learning the meaning of new sounds. However, this child still functioned primarily as a child who is deaf and is identified as such throughout this paper. The aided

Table 1. Subject information.

\begin{tabular}{|c|c|c|c|c|c|}
\hline Subject & Location & $\begin{array}{c}\text { Chronological } \\
\text { age }\end{array}$ & $S E S^{a}$ & $\begin{array}{c}\text { Unaided } \\
\text { hearing level }\end{array}$ & $\begin{array}{c}\text { Aided } \\
\text { hearing level }\end{array}$ \\
\hline Child A-HOH & School 1 & $5: 3$ & Level II & $86 \mathrm{~dB}^{b}$ & $33 \mathrm{~dB}^{\mathrm{b}}$ \\
\hline Child A-NH & School 1 & $5: 5$ & Level I & Normal & \\
\hline Child B-D & School 2 & $5: 11$ & Level I & $111 \mathrm{~dB}^{\mathrm{b}}$ & $47 \mathrm{~dB}^{\mathrm{c}}$ \\
\hline Child B-NH & School 2 & $5: 5$ & Level II & Normal & \\
\hline Child C-D & School 3 & $5: 6$ & Level II & $105 \mathrm{~dB}^{\mathrm{b}}$ & Unknown \\
\hline Child C-NH & School 3 & $5: 6$ & Unavailable & Normal & \\
\hline
\end{tabular}

Note. All children were Caucasian females who had language within normal limits (see Table 2).

a SES was figured using the Two Factor Index of Social Position (Hollingshead, 1957).

b Pure tone average.

c Sound detection with a newly implanted cochlear implant. 
Table 2. Results of language assessment.

\begin{tabular}{|c|c|c|c|}
\hline \multirow[t]{2}{*}{ A-HOH } & $\begin{array}{l}\text { Expressive One Word Picture Vocabulary Test } \\
\text { (Gardner, 1979) }\end{array}$ & Complete Battery & 73 \\
\hline & Bracken Basic Concept Scale (Bracken, 1984) & Complete Battery & 32 \\
\hline \multirow[t]{3}{*}{$\mathrm{A}-\mathrm{NH}$} & Test of Language Development--Primary & Picture Vocabulary & 91 \\
\hline & & Sentence Imitation & 50 \\
\hline & & Grammatical Completion & 63 \\
\hline \multirow[t]{3}{*}{ B-D } & $\begin{array}{l}\text { Rhode Island Test of Language Structure } \\
\text { (Engen \& Engen. 1983) }\end{array}$ & Complete Battery & 99 \\
\hline & Assessing Semantic Skills through Everyday Themes & Receptive Total & 52 \\
\hline & (Barrett, Zachman, \& Huisingh, 1988) & Expressive Total & 83 \\
\hline \multirow{2}{*}{ B-NH } & & Sentence Imitation & 91 \\
\hline & & Grammatical Completion & 63 \\
\hline \multirow[t]{4}{*}{ C-D } & Grammatic Assessment of Elicited Language- & Comprehensive & 50 \\
\hline & Pre-Sentence Level & Prompted Production & 45 \\
\hline & (Moog, Kozak, \& Geers, 1983) & Imitated Production & 25 \\
\hline & $\begin{array}{l}\text { Expressive One Word Picture Vocabulary Test } \\
\text { (Gardner, 1979) }\end{array}$ & Complete Battery & 25 \\
\hline \multirow[t]{5}{*}{$\mathrm{C}-\mathrm{NH}$} & Test of Language Development-Primary & Picture Vocabulary & 84 \\
\hline & (Newcomer \& Hammıll, 1988) & Oral Vocabulary & 37 \\
\hline & & Grammatical Understandıng & 25 \\
\hline & & Sentence Imitation & 50 \\
\hline & & Grammatical Completion & 63 \\
\hline
\end{tabular}

thresholds of one child (C-D) were not available. The subject $(\mathrm{A}-\mathrm{HOH})$ with the aided hearing loss in the mild range is referred to as $\mathrm{HOH}$ throughout the paper.

Subject A-HOH is the youngest of three children in her family. She was identified with a severe sensorineuralbilateral hearing loss at 16 months of age, at which time she received amplification. Her cause of deafness is unknown. During data collection, she used a binaural FM system in the classroom for amplification. She used oral (spoken) communication.

Subject B-D, who is deaf, became the youngest of three children in her family when she was adopted at 2:7 (years:months). The cause of deafness is unknown. She was identified as having a profound sensorineural-bilateral hearing loss at 18 months and received amplification when she was 2 years old. Six months before data collection, she was implanted with a cochlear implant. Because she was still learning to use her cochlear implant, the aided hearing level of $47 \mathrm{~dB}$ is considered only an estimate of true hearing ability. She used the cochlear implant and a monaural personal aid in the classroom. No FM system was used. She used signed and spoken communication.

At the time of data collection, Subject C-D, who is deaf, lived at home with her older half-brother and her younger sister. The cause of deafness is unknown. She was identified as having a profound sensorineural-bilateral hearing loss at 20 months and received amplification at 21 months of age. At the time of data collection, she wore a binaural FM system in school during observation. She used signed and spoken communication.

All subjects were required to have been enrolled in their kindergarten class for at least 3 months before the beginning of this study. This enrollment reduced the likelihood that familiarization of the subjects to the classroom, teacher, and/or peers would confound the types of interactions observed (e.g., Lederberg et al., 1986; Levy Shiff \& Hoffman, 1985).

Each child dyad attended a different school and the atmosphere of each classroom varied depending on the teaching philosophy of the teacher. In School 1, the classroom consisted of group activities that were frequently conducive to many interactions. The classroom in School 2 consisted mostly of seat work and some free play time that was conducive to interactions. The classroom in School 3 consisted of both seat work as well as group work, which was especially conducive to interactions.

The children who are deaf/HOH selected for use in this study were enrolled in the same classroom as the "match" with NH described in Table 1. School 1 and School 2 were located in suburban areas of a large midwestern city. School 3, an urban school, was located in a nearby midwestern city.

Each of the subjects who is deaf/HOH was the only identified student in the classroom with a severe or 
profound unaided hearing loss. However, a child identified as mildly hearing impaired also attended School 1 with subject $\mathrm{A}-\mathrm{HOH}$. The child with a mild hearing loss wore a hearing aid and functioned as a child with NH. An interpreter was not provided for the children in School 1. The subjects at Schools 2 and 3 (B-D and C-D) each had an interpreter assigned to them during their entire school day. The interpreter at School 2 sat with subject B-D and was accessible to the child whenever needed. The interpreter in the classroom at School 3 interpreted lessons and sat with subject C-D part of the day. However, she also functioned as a teacher's aide during a small part of the day and worked with other children in the classroom. The interpreter was accessible to subject C-D, but not necessarily within a close proximity for easy access.

\section{PROCEDURE}

The six subjects were videotaped on 3 separate days for approximately 15 minutes per session. Approximately 10 minutes of data from each tape were randomly selected for coding, resulting in a total of 30 minutes of data per subject. On each visit, the investigator spent time in the classroom with the videotape equipment before actual taping in order to minimize any novelty effect that might occur. The matched subjects were videotaped for approximately 15-20 minutes when the children were given the same choices by the teacher but chose to participate in different activities (e.g., free play). During actual taping, the investigator videotaped the target subject as unobtrusively as possible by maintaining distance and quiet and not engaging in activities with adults or children. During taping, subjects were involved in activities (e.g., math games, art projects, and puzzles) that were conducive to the occurrence of spontaneous language behaviors.

Interactions between the target subject and significant adults or peers were coded using a modification of the Social Interactive Coding System (SICS) (Rice, Sell, \& Hadley, 1990). SICS is a clinical tool that documents children's spoken initiations and responses in a natural classroom setting as a function of other environmental and child play variables. Initiations and responses with respect to the setting, conversational partner, child's play involvement, and kind of play routines observed are included in the tool. It is possible to identify conditions under which a child successfully initiated conversations through use of this coding system.

The activity, play level, addressee, interactive status, and communication mode of each subject's initiation and response was coded. See Appendix A for definitions of the codes and Appendix B for an example of a data sheet. Activity was coded as the actual activity (e.g., puzzles or math games) in which the subject was involved during the segment. As the subject changed activities throughout the segment, the activity code also was changed.

Play level was recorded as solitary (sol), adjacent (adj), or social interactive (int). Each time the subject changed play levels (e.g. solitary, adjacent, or social interactive), the play level was recorded. Solitary play occurred if the subject played alone and with nobody else within a $5^{\prime}$ radius. The subject was involved in adjacent play when other children or adults (excluding the observer) were within a $5^{\prime}$ radius but the target subject was not interacting with them. The play level was coded as social interactive when the target subject was playing with or interacting with another child or adult. These interactions could be unspoken (e.g., a head nod), spoken, or signed.

The person to whom the subject was talking, the "addressee," also was recorded. The notation of the addressee was recorded as "general" if the subject initiated to no specific person. Although numerous interactions occurred between the children who are deaf and their interpreters, only the interactions between the children in the class were of interest in this study.

Interactive status was recorded each time the subject took a turn in an interaction. Interactive status included three types of turns (i.e., initiation, repetition, response). Initiation was defined as any verbal or nonverbal act that was clearly not a continuation of an existing interaction. A repetition was defined as a repeat of the original utterance that was either exactly the same or a modified version of the original attempt. A response was defined as any observable reply, gesture, or action to an initiation. Along with the interactive status, the communication mode also was recorded. The following modes were possible: a spoken word (SW), a vocalization (V), a sign (S), a gesture $(\mathrm{G})$, an action (A), or any combination.

An interaction was considered terminated when a partner did not respond within 5 seconds. The termination of an interaction was marked with an (x) after the last turn. Thirty minutes of interactions were then coded by one of the authors. Ten minutes of each 30-minute sample were coded by a graduate student for reliability purposes. The overall interjudge reliability was $93 \%$.

\section{RESULTS}

The number of successful and unsuccessful initiations, activity, play level, partner, and mode of initiation are reported in Appendix C. An initiation was considered successful if the child received a response to initiation. Because the number of initiations was of particular interest in this study, analysis of the repetition and response type of interactions was not performed except for including these in the count of the total number of interactions. Furthermore, the play level is not addressed in the results because it was determined that this was controlled by the teaching philosophy of the classroom teacher. Table 3 shows no pattern in the interactions of subjects who are $\mathrm{D} / \mathrm{HOH}$. The number of interactions ranged from 16 (subject B-D) to 76 (subject $\mathrm{A}-\mathrm{HOH}$ ). The average length of the interaction for the $\mathrm{D} / \mathrm{HOH}$ subjects was similar, ranging from 2.1 (subject B-D) to 2.9 (subject C-D). Subject A-HOH had a higher frequency of interactions per minute $(2.5)$ than the subjects who are deaf $(0.5$ and 0.7$)$. 
Table 4 includes data specific to the communicative acts coded as initiations, that is any verbal or nonverbal act that was not a continuation of an existing interaction. Subjects who are $\mathrm{D} / \mathrm{HOH}$ initiated interactions successfully $42-67 \%$ of the time. When initiating to more than one person, Subject C-D was never successful and subjects A-HOH and B-D were successful less than $50 \%$ of the time. Only the subject who is $\mathrm{HOH}$ was successful when initiating conversations that were not accompanied by actions or gestures.

When comparing the interactions of peers with $\mathrm{NH}$ (see Table 3), the results were more similar across the three reported categories than they were with subjects who are D/HOH. Subject A-NH consistently produced a larger total number, longer, and more frequent interactions than subjects $\mathrm{B}-\mathrm{NH}$ and $\mathrm{C}-\mathrm{NH}$. When comparing the initiations of peers with $\mathrm{NH}$ (see Table 4), subject C-NH consistently produced fewer successful initiations, fewer successful initiations to more than one person, and fewer successful initiations that were not accompanied by an action or gesture. Both subject A-NH and B-NH were successful 50\% of the time they initiated without actions or gestures.

Reviewing the interactions of each dyad separately (see Table 3 and Table 4), subject A-HOH produced a greater number of total interactions and a greater average length and frequency of interactions than did the peer with $\mathrm{NH}$. The two subjects produced a similar percentage of total successful initiations and successful initiations without actions or gestures. Subject B-NH produced a higher number of total interactions as well as average length and frequency of interaction than were produced by B-D. This pattern was repeated for the percentage of total successful initiations, initiations to more than one person, and initiations unaccompanied by an action or gesture. No pattern was apparent for initiations of subjects $\mathrm{C}-\mathrm{D}$ and $\mathrm{C}$ NH. Subject C-NH made no attempt to initiate to more than one person. Subject $\mathrm{C}-\mathrm{D}$ made no attempt to initiate without an action or gesture.

When the interactions of all subjects are compared (see Table 3), there is no obvious pattern of results. Dyad A$\mathrm{HOH}$ and $\mathrm{A}-\mathrm{NH}$ produced a similar and higher number of total interactions and a higher frequency of interactions than the other two dyads. In these remaining two dyads, the subject with NH produced a higher number and frequency of interactions. All subjects were similar in the length of their interactions (2.1 to 2.9). The subjects who are $\mathrm{D} / \mathrm{HOH}$ in dyads $\mathrm{A}$ and $\mathrm{C}$ produced longer average length of interactions than did their peers with $\mathrm{NH}$. When the initiations of all subjects are compared (see Table 4), no pattern emerges.

Table 3. Total number, length, and frequency of interactions with peers.

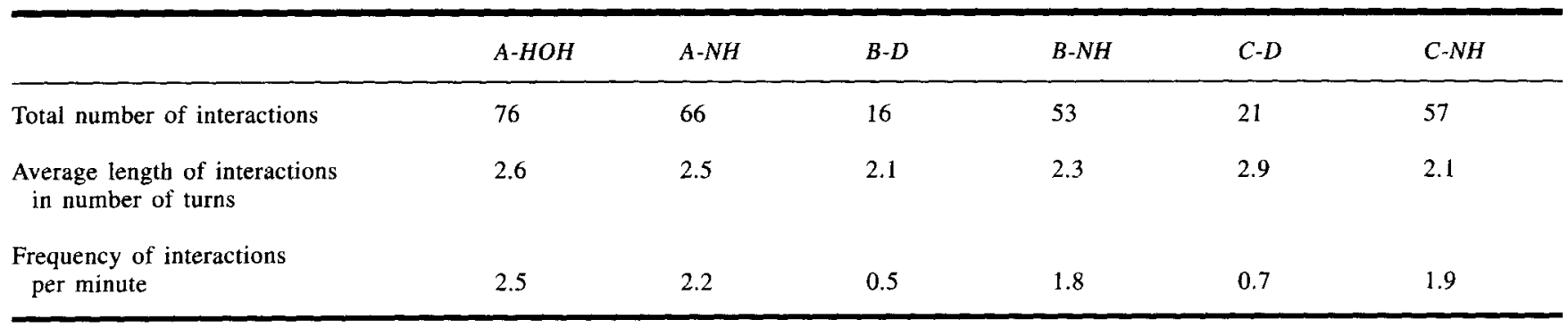

Key. A-HOH-child who is $\mathrm{HOH}$ B-NH-child with NH and matched to B-D. C-D-child who is deaf.
B-D-child who is deaf.

C-NH-child with NH and matched to C-D.

Table 4. Percentage of successful initiations to peers.

\begin{tabular}{|c|c|c|c|c|c|c|}
\hline & A-HOH & $A-N H$ & $B-D$ & $B-N H$ & $C-D$ & $\mathrm{C}-\mathrm{NH}$ \\
\hline Total number of interactions & 76 & 66 & 16 & 53 & 21 & 57 \\
\hline Successful initiations & $\begin{array}{l}60 \% \\
(29 \text { of } 48)\end{array}$ & $\begin{array}{l}64 \% \\
(16 \text { of } 25)\end{array}$ & $\begin{array}{l}42 \% \\
(5 \text { of } 12)\end{array}$ & $\begin{array}{l}56 \% \\
(9 \text { of } 16)\end{array}$ & $\begin{array}{l}67 \% \\
(4 \text { of } 6)\end{array}$ & $\begin{array}{l}37 \% \\
(10 \text { of } 27)\end{array}$ \\
\hline $\begin{array}{l}\text { Successful initiations to } \\
\text { more than one person }\end{array}$ & $\begin{array}{l}44 \% \\
(4 \text { of } 8)\end{array}$ & $\begin{array}{l}14 \% \\
(1 \text { of } 7)\end{array}$ & $\begin{array}{l}25 \% \\
(1 \text { of } 4)\end{array}$ & $\begin{array}{l}33 \% \\
(2 \text { of } 6)\end{array}$ & $\begin{array}{l}0 \% \\
(0 \text { of } 2)\end{array}$ & $\begin{array}{l}\text { No } \\
\text { Attempt }\end{array}$ \\
\hline $\begin{array}{l}\text { Successful initiations } \\
\text { unaccompanied by an } \\
\text { action or gesture }\end{array}$ & $\begin{array}{l}53 \% \\
(10 \text { of } 19)\end{array}$ & $\begin{array}{l}53 \% \\
(7 \text { of } 13)\end{array}$ & $\begin{array}{l}0 \% \\
(0 \text { of } 2)\end{array}$ & $\begin{array}{l}50 \% \\
(6 \text { of } 12)\end{array}$ & $\begin{array}{l}\text { No } \\
\text { Attempt }\end{array}$ & $\begin{array}{l}20 \% \\
(3 \text { of } 15)\end{array}$ \\
\hline
\end{tabular}

Key. A-HOH-child who is $\mathrm{HOH}$. B-NH-child with $\mathrm{NH}$ and matched to B-D.
A-NH-child with $\mathrm{NH}$ and matched to A-HOH. C-D-child who is deaf.
B-D-child who is deaf.

C-NH-child with $\mathrm{NH}$ and matched to C-D. 


\section{DISCUSSION}

Interactions with peers are important elements in a child's school day. Children possibly learn as much from interactions with their friends as they do from their teachers. From past research, it is known that children who are deaf/HOH do not always have the advantage of being a part of communicative interactions with their peers with NH. Most research has found that breakdowns occur because the initiator fails to successfully begin the communication act. Because of the importance of peer communication, this research project was designed to investigate the interactions of children who are deaf/HOH and their peers with NH. All questions addressed in the study are discussed briefly below, followed by a discussion of the results that these researchers found most interesting.

The authors investigated several areas of interest. The first set of questions examined the number of interactions, the average length of the interactions, and the frequency of interactions by the subjects with $\mathrm{NH}$ as compared to the subjects who are deaf/HOH. The interactions of subjects A$\mathrm{HOH}$ and A-NH were similar to the results of work by Vandell and George (1981), who found that there was no significant difference in the number of interactions between peers who are deaf/HOH and those with $\mathrm{NH}$.

Also in the Vandell and George (1981) study, there was a significant difference between children who are deaf/ $\mathrm{HOH}$ and children with $\mathrm{NH}$ with regard to the amount of time spent in interactions. In this study, the amount of time spent in interactions was determined by the number of turns in an interaction. Two of the three dyads produced similar average numbers of turns during interactions. Only one dyad (C-D and C-NH) produced an observable difference in the average number of turns. There was almost one complete turn difference favoring the child with $\mathrm{NH}$ in this dyad.

Greenwood, Walker, Todd, and Hops (1981) found that the frequency of interactions by children with $\mathrm{NH}$ ranged from 0.5 to 1.0 interactions per minute. The children in this study with $\mathrm{NH}$ and the child who is $\mathrm{HOH}$ produced frequencies of interactions that were above this previously reported range. Even the two subjects who are deaf fell within the average range for children with $\mathrm{NH}$ reported by Greenwood et al. (1981). The children in the Greenwood et al. (1981) study included children between the ages of 3-8 years. The difference in the age of the children in the Greenwood et al. (1981) study (e.g., 3 years old) and those in this study (e.g., 5 years old) might possibly explain the difference in results.

Classroom structure and encouragement from the teacher may play a role in the number of interactions produced by children, regardless of hearing status, in a classroom. The classroom in School 1 seemed more conducive than the classes in the other schools to conversational interactions. The classroom atmosphere was designed for group activities and the children were encouraged to work together. This seemed to influence subjects $\mathrm{A}-\mathrm{HOH}$ and $\mathrm{A}-\mathrm{NH}$, who produced a larger number of interactions than the other dyads. The classroom in School 2 was designed for seat work with little free play during the class time. Children were encouraged to work by themselves most of the time and few interactions among peers occurred. The classroom in School 3 consisted of seat work and group work. However, on 1 observation day, the children also were given free play time. A higher number of interactions were produced by the subjects in School 3 during this observation than during other observation days in that classroom.

Another purpose of this study was to examine whether there was a difference between children who are deaf/HOH and children with $\mathrm{NH}$ with respect to the number of initiations and the number of successful initiations during 30 minutes of classroom activities. Remember that even though a child produces a higher number of interactions, that does not mean they are necessarily a more successful initiator. Past research has found that children who are deaf/HOH often are unsuccessful initiators (Vandell \& George, 1981; Vandell et al., 1982).

Contrary to these past findings, this study did not find that children with NH always produce a higher percentage of successful initiations than their peers who are deaf/ HOH. In fact, one deaf child (C) produced a higher percentage of successful initiation than her match with NH. This could be a result of the fact that her initiations all involved actions or gestures (e.g., passing the glue), which probably facilitated more initiations. The child who was $\mathrm{HOH}(\mathrm{A}-\mathrm{HOH})$ produced an almost equal percentage of successful initiations as her match with NH. This could be a result of the fact that when subject $\mathrm{A}-\mathrm{HOH}$ initiated, the other children were able to understand her and respond to her initiations. The other deaf child (B-D) produced a higher percentage of unsuccessful initiations than her match with $\mathrm{NH}$.

Each child who served as a subject for the study differed on a variety of factors related to the number of initiations she produced. Subject A-HOH had a higher number of initiations than her peer with NH. This may be attributed to the fact that she used oral communication (speech) that was intelligible to her peers. Subject B-D chose to initiate her conversations to her interpreter instead of her peers. Because only peer interactions were included in the data for this study, subject B-D had a lower number of initiations than her peer with NH. Subject C-D did not have intelligible speech, did not seem to use her interpreter effectively, and spent a great deal of time watching the activity elsewhere in the room. This behavior possibly contributed to her lower number of initiations as compared to her peer with $\mathrm{NH}$.

Research by Ervin-Tripp (1979) suggested that children were more successful when the conversation was between two children rather than among a larger group at certain developmental periods. Similarly, all children (deaf/HOH and $\mathrm{NH}$ ) in this study had a higher percentage of successful initiations to one peer than to a larger group of peers.

The results of this study were inconclusive as to whether children who are deaf/HOH were more or less successful than their peers with $\mathrm{NH}$ when initiating to more than one person. It was interesting to note that subject $\mathrm{A}-\mathrm{HOH}$, who produced a higher percentage of successful initiations to a group of peers than her match with $\mathrm{NH}$, initiated only 
when it was her turn during a game played with four peers. Subject B-D often was unsuccessful when initiating to more than one peer. Subject C-D did not attempt to initiate to more than one peer.

The present study substantiated the finding that children with NH modify their communication because of familiarity to the specific subject who is deaf/HOH (Lederberg et al., 1986; Vandell et al., 1982). On several different occasions during observations in two of the classrooms, children with $\mathrm{NH}$ who were familiar with the subject who is deaf/HOH seemed to modify their communication by using a sign or attempting to sign to the subject who is deaf $/ \mathrm{HOH}$. Interestingly, neither of the children who are deaf/HOH signed back to peers, even though they were capable of doing so. The subjects who are deaf/HOH also modified their communication by not using sign to their peers with NH. This is most likely because they had learned to codeswitch, having discovered that signing to peers was not a successful way to communicate, and that using spoken words, gestures, and actions often was effective.

Subject C-D seemed to be more like the subjects of past research on the interactions of children who are deaf/HOH. Factors such as not relying on oral communication, not being highly intelligible, and not using her interpreter to interact with peers all contributed to the results of her data analysis as being similar to the results of past research. On the other hand, when this child did initiate, she was highly successful.

The present study was limited in the number and variety of subjects utilized. making it less generalizable to the general populations of children who are deaf or hard of hearing. The present study was unable to control for teacher philosophy with regard to classroom structure, which might have limited some subjects in their opportunities for interaction. Further study needs to be done in this area, especially in regard to the number of subjects, use of the interpreter, and use of actions and gestures when communicating.

\section{IMPLICATIONS FOR INTERVENTION}

Results of this study were that children's interactions increase in number when they are enrolled in a classroom where the philosophy of the teacher allowed and even encouraged children to interact with each other. A child who has numerous opportunities to interact may be more willing to interact, even though the interaction may not always be successful. The more times the child interacts, the more chances there are to learn what types of interactions are successful. Therefore, a child who is deaf/HOH might benefit from being placed in a classroom where interactions are allowed and even encouraged by the teacher.

Children might be encouraged to participate in group discussions or group games, allowing them more opportunities to initiate conversations in larger group situations. Again, the more opportunities the child has to interact in group situations, the more likely he or she may be to increase initiations and to learn from both successful and unsuccessful attempts.

Subjects in this study who are deaf were more successful when they used an action or gesture as part of their initiation. Children who are deaf as well as children with $\mathrm{NH}$ might be encouraged to use actions and gestures in their initiations to supplement their vocalizations, spoken words, or signs.

Although data regarding adult interactions were not analyzed in this study, it was noted that the subjects who are deaf relied on their interpreters as partners for communication. However, the subjects did not use the interpreters to facilitate interactions with peers. Children who are deaf/HOH and their peers with $\mathrm{NH}$ could be encouraged to use educational interpreters to facilitate communication during free play activities. Because the subjects who are deaf have normal language abilities, the interpreters also could encourage communicative interactions between peers. This would seem to be an important area in need of further research.

\section{REFERENCES}

Arnold, D., \& Tremblay, A. (1979). Interaction of deaf and hearing preschool children. Journal of Communication Disorders, $12,245-251$.

Barrett, M., Zachman, L., \& Huisingh, R. (1988). Assessing semantic skills through everyday themes. East Moline, IL: LinguiSystems, Inc.

Bracken, B. A. (1984). Bracken Basic Concept Scale. San Antonio, TX: The Psychological Cooperation.

Coie, J. D., \& Kupersmidt, J. B. (1983). A behavioral analysis of emerging social status in boys' groups. Child Development, 54, $1400-1416$.

Conti-Ramsden, G., \& Friel-Patti, S. (1983). Mothers' discourse adjustment to language-impaired and non-language-impaired children. Journal of Speech and Hearing Disorders, 48, 360-367.

Craig, H. K., \& Gallagher, T. M. (1983). Adult-child discourse: The conversational relevance of pauses. Journal of Pragmatics, $7,347-360$

Cunningham, C. E., Reuler, E., Blackwell, J., \& Deck, J. (1981). Behavioral and lingurstic developments in the interactions of normal and retarded children with their mothers. Child Development, 52, 62-70.

Engen, E., \& Engen, T. (1983). Rhode Island Test of Language Structure. Baltimore, MD: University Park Press.

Ervin-Tripp, S. (1979). Children's verbal turn-taking. In E. Ochs \& B. B. Schieffelin (Eds.), Developmental pragmatics (pp. 391414) New York: Academic Press.

Ervin-Tripp, S., \& Gordon, D. (1986). The development of requests. In R. L. Schiefelbusch (Ed.), Language competence assessment and intervention (pp. 61-95). San Diego: CollegeHill Press.

Gardner, M. F. (1979). Expressive One-Word Picture Vocabulary Test. Novato, CA: Academic Therapy Publications.

Greenwood, C. R., Walker, H. M., Todd, N. M., \& Hops, H. (1981). Normative and descriptive analysis of preschool free play social interaction rates. Journal of Pediatric Psychology, 6 , 343-367. 
Greenberg, M. T. (1980). Mode use in deaf children: The effects of communication method and communication competence. Applied Psycholinguistics, 1, 65-79.

Guralnick, M. J. (1980). Social interactions among preschool children. Exceptional Children, 46, 248-253.

Hadley, P. A., \& Rice, M. L. (1991). Conversational responsiveness of speech-and language-impaired preschoolers. Journal of Speech and Hearing Research, 34, 1308-1317.

Hollingshead, A. B., \& Redlich, F. (1958). Socıal class and mental illness; a community study. New York: John Wiley and Sons.

Lederberg, A. R., Ryan, H. B., \& Robbins, B. L. (1986). Peer interactions in young deaf children: The effect of partner hearing status and familiarity. Developmental Psychology, 22, 691-700.

Levy Shiff, R., \& Hoffman, M. A. (1985). Social behavior of hearing-impaired and normally-hearing preschoolers. The British Journal of Educational Psychology, 55, 111-118.

Moog, J. S., Kozak, V. J., \& Geers, A. E. (1983). Grammatical Analysis of Elicited Language-Pre-Sentence Level. St. Louis, MO: Central Institute for the Deaf.

Mueller, E. (1972). The maintenance of verbal exchanges between young children. Child Development, 43, 930-938.

Newcomer, P., \& Hammill, D. D. (1988). Test of Language Development-Primary. Austin, TX: PRO-ED.

Northcott, W. H. (1978). Integrating the preprimary hearing impaired child. In M. J. Guralnick (Ed.), Early intervention and the integration of handicapped and nonhandicapped children (pp. 207-238). Baltimore: University Press.

Rice, M. L., Sell, M. A., \& Hadley, P. A. (1990). The social interactive coding system (SICS): An on-line, clinically relevant descriptive tool. Language, Speech, and Hearing Services in Schools, 21, 2-14.

Rice, M. L., Sell, M. A., \& Hadley, P. A. (1991). Social interactions of speech-and language-impaired children. Journal of Speech and Hearing Research, 34, 1299-1307.

Schildroth, A. (1988). Recent changes in the educational placement of deaf students. American Annals of the Deaf, 133, 61-67.

Vandell, D. L., Anderson, L. D., Ehrhardt, G., \& Wilson, K. S. (1982). Integrating hearing and deaf preschoolers: An attempt to enhance hearing children's interactions with deaf peers. Child Development, 53, 1354-1363.

Vandell, D. L., \& George, L. B. (1981). Social interaction in hearing and deaf preschoolers: Successes and failures in initiations. Child Development, 52, 627-635.

Received September 28, 1993

Accepted June 20, 1994

Contact author: Barbara Luetke-Stahlman, PhD, Director Deaf Education, University of Kansas Medical Center, 3901 Rainbow Blvd., Kansas City, KS 66160-7605. 


\section{APPENDIX A}

\section{Codes}

\section{Activity}

The actual activity in which the child is involved is recorded. If the child changes activities during a coding segment, the change in activities is recorded as well.

Play level

Solitary (Sol) - the child plays by him or herself with no other children in a 5 ' radius (e.g., the target child is sitting by him or herself in the corner reading a book).

Adjacent (Adj)-the child plays by him or herself, but one or more other children are within a 5 ' radius of the target child (e.g., the target child is working on an art project at the table with other children).

Social interaction (Int)-the child plays with at least one other child in an interactive manner with the toys/ materials available in the area (e.g., two or more children building blocks together).

Addressee

The name of the interlocuter is recorded. If the comment is to anyone in general, it is recorded as "general."

Interactive status

Initiation-Any act that is clearly not a part of an existing interaction.

Spoken word initiation (SWI)-intelligible speech (e.g., Can I play?).

Vocalized initiation (VI)-unintelligible use of voice, including laughing and crying.

Signed initiation (SI) - conventional sign language or finger spelling.

Gestural initiation (GI)-hand movement that cannot be found in a sign book; unconventional hand shape (e.g., the child points to a toy to show another child what he or she is talking about).

Action initiation (AI)-gross body act (e.g., a child handing a toy to another child or a child pushing another child).

Bimodal combinations-any combination of the above codes that a child uses simultaneously to convey a message (e.g., the child says, "Give me the dog" and points to the dog).

Repetition-A repetition of the original initiation that is either exactly the same or a modified version of the original attempt.

Spoken word repetition (SWRep)-intelligible speech (e.g., Can I play?).
Vocalized repetition (VRep)-unintelligible use of voice, including laughing and crying.

Signed repetition (SRep)-conventional sign language or finger spelling.

Gestural repetition (GRep)-common nonverbal signals of head, hands, or body, including pointing to and showing objects (e.g., the child points to a toy to show another child something about it).

Action repetition (ARep)-gross body act (e.g., a child handing a toy to another child or a child pushing another child).

Bimodal combinations-any combination of the above codes that a person uses simultaneously to convey a message (e.g., the child says, "Give me the dog" and points to the dog).

Interpreter (Int) - the interpretations of spoken words or signed interactions in the classroom for the child who is deaf or hard of hearing (e.g., the teacher tells the child to do something and then the interpreter signs that to the child who is deaf or hard of hearing).

Response-Any observable reply, gesture, or action to the initiation.

Spoken word response (SWR)-intelligible speech (e.g., I can play?).

Vocalized response (VR)--unintelligible use of voice, including laughing and crying.

Signed response (SR) - conventional sign language or finger spelling.

Gestural response (GR)—common nonverbal signals of head, hands, or body, including pointing to and showing objects (e.g., the child points to a toy to show another child something about it).

Action response (AR) - gross body act (e.g., a child handing a toy to a child or a child pushing a child).

Bimodal combinations - any combination of the above codes that a child uses simultaneously to convey a message (e.g., the child says, "Thank you" and simultaneously signs thank you)

\section{End of an interaction}

An ( $x$ ) is placed on the data sheet after the last turn of an interaction.

Codes and some definitions adapted from Rice et al. (1990). Some definitions adapted from Greenberg (1980). 


\section{APPENDIX B}

Data Sheet

Name: $\underline{A-H O H}$

Age: 5:3

Site: School 1

Time: 5 minutes

Observation Period: \#9

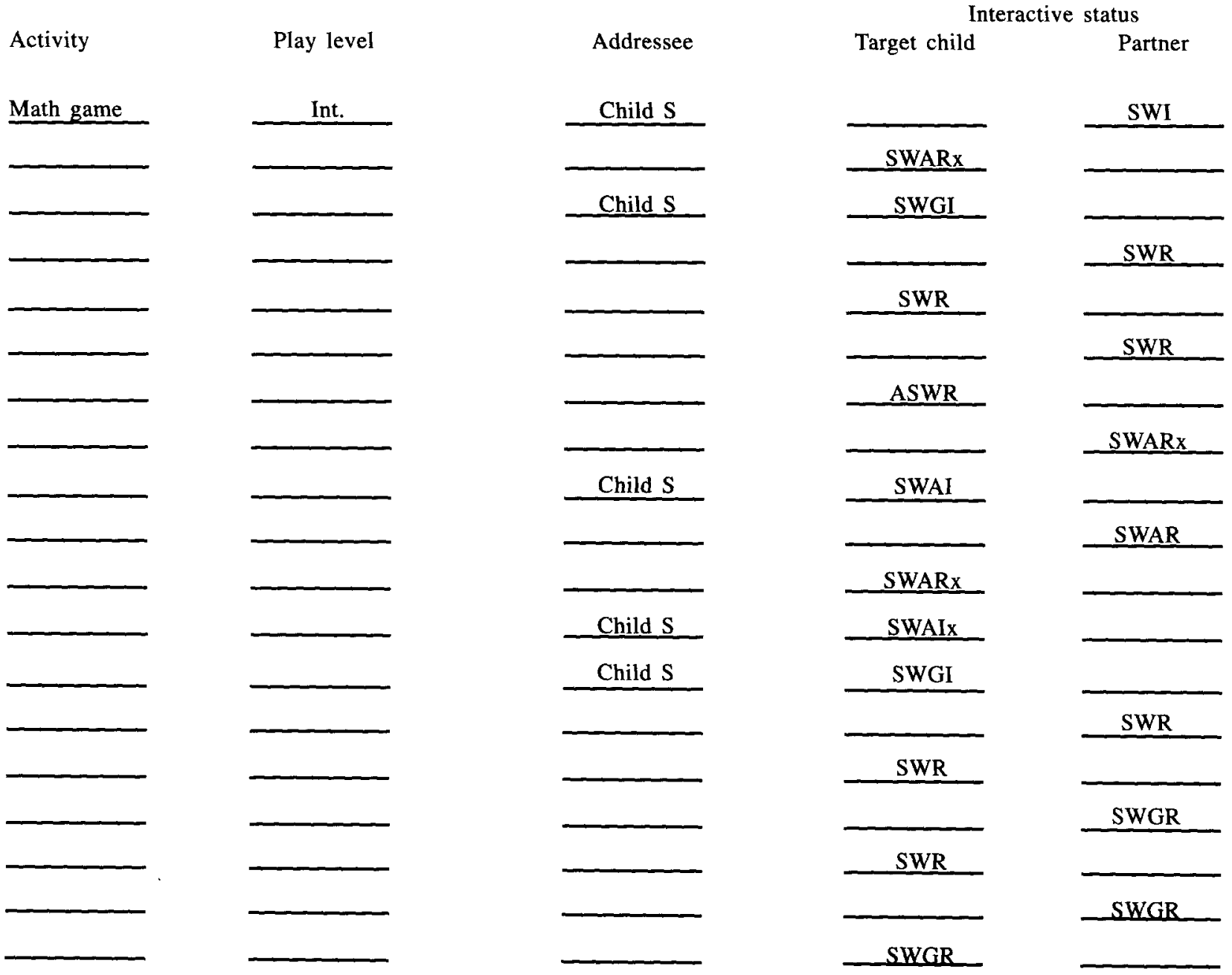




\section{APPENDIX C}

\section{Raw Data}

Activity

Play level

Int. (27)

Puzzle (12)

Worksheet (2)

Math game (12)

Game (3)

Adj. (2)
$\#$ of successful
initiations $=29$

\# of unsuccessful

initiations $=19$

Adj. (2)
Puzzle (7)

Worksheet (2)

Math game (9)

Game (1)
Partner

SWI (10)

SWAI (8)

SWVAI (1)

SWAGI (3)

AGI (1)

SWGI (4)

AI (2)

Childr

Group of 5 (1)

Int. (17)

Child S (9)

Child H (6)

Children H \& B (1)

General (3)

SWI (9)

SWGI (3)

VGI (1)

SWAI (6)

\section{A-NH}

\# of successful

initiations $=16$

Game (5) Int. (13)

Puzzle (5)

Adj. (3)

Worksheet (3)

Math game (3)

Game (7)

Puzzle (2)

Int. (8)

Sol. (1)

Child M (12)

Child N (1)

Child B (1)

Child Be (1)

Group of 5 (1)

\# of unsuccessful

initiations $=9$

Art project (2)

House area (3)

of successfu

initiations $=5$

\# of unsuccessful

initiations $=7$
House area (7)

Adj. (7)

\section{Int. (2)}

Adj. (3)

\section{B-NH}

\# of successful

initiations $=9$

\# of unsuccessful

initiations $=7$

Blocks (1)

Computer game (3)

Worksheet (3)

$\begin{array}{ll}\text { Blocks (2) } & \text { Int. (5) } \\ \text { Computer game (5) } & \text { Adj. (4) }\end{array}$

Worksheet (2)
Child B (1)

Child N (1)

General (1)

Child B (1)

Child J (1)

Child N (1)

Children J \& S (1)

General (2)

Group of 3 (1)
SWI (7)

SWAI (5)

SWGI (2)

AI (2)

SWI (6)

SWAI (2)

AVI (1)

\begin{tabular}{ll} 
General (2) & Group of $3(1)$ \\
\hline
\end{tabular}

C-D

\# of successful

1nitiations $=4$

\# of unsuccessful

initiations $=2$
Worksheet (3)

Cars (1)

Worksheet (2)

Adj. (2)
Int. (1)

Adj. (3)
Child B (3)

Child A (1)

Group of $4(2)$
GVI (1)

SGVI (1)

AI (2)

ASI (1)

VGI (2)

VAI (3)

VI (2)
SWI (6)

SWAI (1)

SWGI (2)

SWI (6)

SWAI (1)

\section{Downloaded From: http://shss.pubs.asha.org/ by a University of Kansas - Libraries, Watson User on 02/17/2015 \\ Terms of Use: http://pubs.asha.org/ss/Rights_and_Permissions.aspx}




\section{C-NH}

\# of successful

initiations $=10$

Game (3)

Math game (3)

Worksheet (4)

Art project (3)

Math game (2)

Worksheet (7)

Game (3)

Blocks
Int. (4)

Adj. (6)

Child D (1)

Child C (1)

Child A (6)

Child G (2)

Int. (5)

Adj. (12)
Child B (7)

Child M (1)

General (2)

Group of 4 (7)
SWAI (3)

SWI (3)

AI (4)

SWI (12)

SWAI (2)

SWGI (1)

AI (2)

Key. The number appearing in parentheses is the number of times that particular behavior was coded in the sample.

Play level codes are Int-Social Interactive, Adj-Adjacent, Sol-Solitary.

Mode codes are all combinations of SW-Spoken Word, S-Sign, V-Vocalization, G-Gesture, A-Action, I-Initiation.

* The child's interpreter was interpreting the interaction with sign and spoken words. 